\title{
pro.posições
}

$e$-ISSN 1980-6248

10.1590/1980-6248-2016-0062

DOSSIÊ: Homeschooling e o direito à educação

\section{Educação Domiciliar: encontrando o Direito}

\section{Homeschooling: Finding the Right}

Édison Prado de Andrade (i)

(i) Advogado privado; gestor da Associação Brasileira de Defesa e Promoção da Educação Familiar (ABDPEF); Doutor pela Faculdade de Educação da USP. educandoemfamilia@gmail.com

Resumo: O presente artigo visa a resgatar as pesquisas internacionais que versam sobre a regulamentação de homeschooling (educação domiciliar), com vistas a contribuir para a elaboração de uma legislação brasileira sobre o assunto. Entendendo que a prática da educação domiciliar deverá ser garantida como um direito compreendido na esfera das liberdades individuais fundamentais e do poder familiar, o autor propõe que o Estado brasileiro promova regulamentação minimalista que pressuponha, inicialmente, que os pais sejam capazes de implementar com sucesso um programa de ensino-aprendizagem com seus filhos, seguindo os métodos e as técnicas propostos pela educação domiciliar e, tanto quanto possível, se desenvolvam relações de cooperação com professores, escolas e outras instituições de ensino e pesquisa, todos orientados pelas finalidades, pelos ideais e pelos princípios insculpidos na legislação que versa sobre a educação nacional.

Palavras-chave: educação, direito, educação domiciliar, direito da criança e do adolescente, família

Abstract: This article aims to articulate international researches dealing with the regulation of bomeschooling, in order to contribute to the shaping of a Bravilian legislation on the subject. Understanding that the practice of homeschooling should be guaranteed as a right in the sphere of fundamental individual freedoms and of family power, the author proposes that the Brazilian State should promote only a minimal regulation, one that initially ensures that parents are able to successfully implement a teaching and learning program with their children, following the methods and techniques proposed by homeschooling, while, as much as possible, developing cooperative relations with teachers, schools and other educational and research institutions, all guided by the purposes, ideals and principles inscribed in the legislation that deals with national education.

Keywords: education, right, homeschooling, right of children and adolescents, family 


\section{pro.posições}

\section{Introdução}

Questão tormentosa aos que se dedicam a pensar e trabalhar para que seja assegurada às crianças e aos adolescentes brasileiros educação universal e de qualidade é conceber-se a Educação Domiciliar ${ }^{1}$ como um direito, sem, ao mesmo tempo, colocar-se em risco o próprio direito à educação da criança e do adolescente, além de outros direitos fundamentais. Provavelmente, também por isso, entre outras razões, ainda não se tenha tido êxito em aprovar no parlamento nacional um único projeto de lei que garanta o direito à Educação Domiciliar no Brasil - embora se busque fazer isso há décadas, desde que se passou a entender, no Brasil, que a escolarização universal e obrigatória exclui, necessariamente, outros modos de garantir e promover o direito à educação.

$\mathrm{Na}$ esfera internacional existe variada legislação sobre o tema, a qual prescreve sobre os seguintes aspectos relativos à educação domiciliar: (i) o reconhecimento da educação domiciliar como um modelo educacional legítimo, com fundamento em um direito fundamental de liberdade; (ii) a regulamentação legal ou infralegal; (iii) o processo de fiscalização ou inspeção promovido pelos órgãos e agentes estatais.

Os limites de intervenção do Estado na esfera das liberdades individuais é ponto central na legislação, quando se discute o direito. Entretanto, há outras questões, como a obrigatoriedade da matrícula escolar; a relação dos educandos com o sistema escolar e as unidades escolares; as especificidades do controle e da avaliação dos resultados do ensinoaprendizagem domiciliar, promovidos pelos órgãos de ensino e por outros órgãos do Estado; a qualificação do pai/mãe/responsável legal que pretenda promover a educação domiciliar da criança ou do adolescente.

Antes de adentrarmos à análise propositiva da legislação no Brasil, faremos uma revisão resumida da legislação internacional.

\footnotetext{
${ }^{1}$ Usaremos esta terminologia para nos referirmos à educação de crianças ou adolescentes, realizada de modo desescolarizado e sob o protagonismo dos pais do educando. Preferimos a terminologia Educação Familiar Desescolarizada, por entendermos que ela é mais apta para representar o modelo educacional levando em conta suas nuanças. A esse respeito, ver a tese de doutoramento intitulada Educação familiar desescolarizada e o direito da criança e do adolescente: relevância, limites e possibilidades na ampliação do direito à educação (Andrade, 2014).
} 


\section{pro.posições}

\section{Estados Unidos da América}

Nesse país encontramos o maior número de pesquisas sobre o assunto, conforme nos informam Kunzman e Gaither (2013, p.31), certamente em razão de que é nele que se encontra o maior número de homeschoolers ${ }^{2}$ no mundo. Segundo os autores, a Suprema Corte dos EUA ainda não chegou a julgar um caso bomeschooling ${ }^{3}$, mas os que defendem o direito dos pais à sua escolha como alternativa à escolarização obrigatória afirmam repetidamente que se trata de um direito protegido pela primeira emenda e também pela décima quarta da Constituição Federal ${ }^{4}$ daquele país. A primeira emenda, ou "cláusula do livre exercício", dispõe que

o Congresso não fará lei relativa ao estabelecimento de religião ou proibindo o livre exercício desta; ou restringindo a liberdade de palavra ou de imprensa; o direito do povo de reunir-se pacificamente e de dirigir petições ao governo para a reparação de seus agravos (Corwin, 1986, p.229).

A décima quarta emenda, ou cláusula do "devido processo legal", trata de outro direito fundamental igualmente valioso aos sistemas republicanos e democráticos, o qual teria dado origem ao "direito à privacidade", também fundamental. O texto constitucional segue, em tradução de Corwin (1986):

Todas as pessoas nascidas ou naturalizadas nos Estados Unidos e sujeitas à sua jurisdição são cidadãs dos Estados Unidos e dos Estados em que residem. Nenhum Estado fará ou executará qualquer lei restringindo os privilégios ou imunidades dos cidadãos dos Estados Unidos; nem privará qualquer pessoa da vida, liberdade ou propriedade sem processo legal regular; nem negará a qualquer pessoa dentro de sua jurisdição a igual proteção das leis. (pp.299-300)

Segundo Kunzman e Gaither (2013, pp. 23-24), as pesquisas encontram um consenso entre os juristas de que o argumento da décima quarta emenda é o mais convincente, porque anteriormente o mesmo tribunal já havia reconhecido o direito dos pais de educar seus filhos.

\footnotetext{
${ }^{2}$ Estudantes em homeschooling.

3 Denominação referenciada internacionalmente para o fenômeno dos pais que promovem diretamente a educação de seus filhos, no Brasil mais conhecido como educação domiciliar.

${ }^{4}$ Essas emendas encontram correspondentes no artigo 5. ${ }^{\circ}$ da Constituição da República Federativa do Brasil e constituem-se como cláusulas pétreas em nosso sistema jurídico, não podendo ser modificadas nem mesmo por meio de Emenda Constitucional, apenas por meio de uma nova Constituição, pois essas normas possuem o conteúdo político que distingue os sistemas republicanos e os estados democráticos de direito dos outros sistemas políticos, como a monarquia e os regimes totalitaristas.
} 


\section{pro.posıções \\ $e$-ISSN 1980-6248}

10.1590/1980-6248-2016-0062

No entanto, segundo os mesmos autores, nenhum tribunal de primeira instância teria reconhecido um direito constitucional ao bomeschooling fundamentado nessa norma constitucional, muito embora diversos estados americanos, por meio de autorização legislativa, já tenham concedido maior autonomia para os homeschoolers que são motivados por razões religiosas do que para os outros (Bach, 2004, como citado em Kunzman \& Gaither, 2013, p.24).

A legislação dos estados da federação daquele país norte-americano é mais complexa do que a da União. ${ }^{5}$ Entre os anos de 1982 e 1988, 28 estados aprovaram nova legislação homeschooling, muitas delas em resposta a decisões judiciais que alegavam que a Constituição Federal e a legislação sobre o assunto eram vagas e deficientes. Lembrando Levy (2009, como em Kunzman \& Gaither, 2013, p.23-24), o resultado dessa proliferação de normas alimentadas por questões político-administrativas de teor público tem tecido uma "colcha de retalhos de leis".

Tal como acontece com o direito constitucional, grande parte da literatura sobre questões legais é normativa, procurando influenciar políticas públicas através da construção de argumentos legais. Normalmente esses argumentos caem em um de dois campos: alguns juristas, e os próprios defensores homeschooling, advogam a favor de nenhuma regulação ou, no máximo, uma regulação reduzida; outros, muitas vezes motivados por preocupações com o bem-estar infantil, a igualdade de gênero, ou a doutrinação ideológica, defendem algum tipo de regulamentação.

Alguns defensores da regulação preconizam um clima mais maximalista, propondo testes de competência para os pais educadores e avaliação curricular, além de testes anuais aplicados à criança ou ao adolescente. Outros advogam por um ambiente regulatório mais minimalista, limitando o registro dos pais à aprovação em testes estaduais e competências básicas em gramática e matemática.

\footnotetext{
${ }^{5}$ O Brasil e os EUA estão organizados política e administrativamente como sistemas republicanos federativos, assim como a quase totalidade das democracias no mundo. Nos EUA, os Estados federados gozavam de soberania política antes de desejar e resolver unirem-se como uma nação. Para isso, abriram mão de sua soberania e de parte de sua autonomia, constituindo assim os Estados Unidos da América, no ano de 1779 d.C. Essa configuração política ainda se mantém hoje, de modo bastante diferente do caso Brasil, no qual a União ainda mantém enorme parcela de poder político-administrativo, o que facilmente se pode comprovar observando os dispositivos da Constituição Federal em vigor, que fixa a organização do Estado, especialmente as competências dos entes federados, e a organização do Sistema Tributário Nacional.
} 


\section{pro.posições \\ $e$-ISSN 1980-6248}

\section{Europa}

O foco principal das pesquisas recentes sobre homeschooling no continente europeu tem sido a adequação do papel e da autoridade do Estado na educação. A regulamentação varia muito na Europa, e continua a mudar ao longo do tempo (Petrie, 2001, como citado em Kunzman \& Gaither, 2013, p.32; Taylor \& Petrie, 2000, como citados em Kunzman \& Gaither, 2013, p.32). Faremos um resumo das condições da regulamentação de homeschooling em alguns países europeus, conforme ${ }^{6}$ Karsten e Blok (2011, pp. 138-152).

$\mathrm{Na}$ comunidade belga de língua holandesa, a Constituição Federal prescreve que os pais podem proporcionar educação domiciliar a seus filhos, devendo informar sua opção às autoridades federais. Desde 2003, eles também devem declarar que cumprem os requisitos relativos à educação. No processo de autorização e controle estatal, o órgão de ensino supervisiona a educação domiciliar por meio de um inspetor que realiza visitas domiciliares e pede aos pais que apresentem todos os documentos relevantes. A presença da criança é desejável, mas não requerida, e o inspetor apenas avalia se os pais cumprem as obrigações estabelecidas. Se eles não cooperam com a avaliação, ou se o inspetor chega repetidamente a conclusões negativas, os pais devem matricular a criança na escola (Vlaams Ministerie van Onderwijs \& Vorming, 2009, como citado em Blok \& Karsten, 2011, p. 141).

Na comunidade belga de língua francesa, a Constituição Federal também garante que os pais possam proporcionar educação domiciliar aos seus filhos em idade escolar, apenas sendo necessário, para isso, informar às autoridades federais sua opção e oferecer ao educando um currículo equivalente ao escolar. O serviço de inspeção para a educação em casa financia as visitas domiciliares, analisa o material e faz perguntas diretamente à criança. Depois de dois resultados negativos sucessivos, os pais devem matriculá-la na escola. Inspeções ocorrem quando a criança completa 8 e 10 anos, mas podem também ser realizadas em outros momentos. E as crianças devem submeter-se a exames escolares nacionais quando atingem as idades de 12 e 14 anos.

$\mathrm{Na}$ Dinamarca, os pais são legalmente responsáveis por garantir que seu filho receba a educação adequada, e a Constituição permite que eles forneçam educação domiciliar, porém devem informar ao município a escolha e fornecer dados sobre o local onde o ensino ocorre e 


\section{pro.posıções}

$e$-ISSN 1980-6248

quem ensina a criança. $\mathrm{O}$ objetivo da inspeção pública é garantir que a criança tenha uma educação adequada, com resultados de aprendizagem comparáveis à escola pública, tal como previsto na lei. Há um teste anual para assegurar que o programa escolar oficial - assim definido pelo Ministério da Educação do país - esteja sendo seguido. Como regra geral, as autoridades locais exigem que as crianças educadas domiciliarmente atinjam médias que estejam em consonância com a média escolar. Se o inspetor verificar que os resultados não são satisfatórios, outra inspeção poderá ser realizada após três meses e, caso subsistam os resultados, poder-se-á obrigar o aluno a ir para a escola pública.

$\mathrm{Na}$ Inglaterra, a educação é obrigatória, mas a frequência escolar não é. Os pais são livres para escolher o tipo de educação que desejam para os seus filhos, e somente requisitos gerais aplicam-se à educação domiciliar. Conforme o artigo 7 do "Education Act", de1996, o pai/a mãe deve fazer com que a criança receba educação em tempo integral que seja eficiente e adequada a sua idade, capacidade e aptidão, e deve prover ainda qualquer educação especial de que ela necessite.

Os pais não são obrigados a comunicar a educação em casa, e as autoridades locais não têm o dever legal de monitorar a qualidade da educação domiciliar. No entanto, se houver razão para acreditar que os pais não estejam oferecendo educação adequada para o seu filho, as autoridades devem pedir a eles mais informações. Se não estiverem satisfeitas com a resposta, uma investigação adicional é realizada, e os pais são convidados a fornecer mais provas. Se permanecer a dúvida, uma ordem de frequência escolar pode ser emitida (Hopwood et al., 2007, como citados em Blok \& Karsten, 2011, pp. 144-145).

Na Finlândia, a educação é obrigatória, e não a frequência escolar. Os pais devem informar o município de sua intenção, e o currículo adotado deverá ser equivalente ao do currículo escolar nacional. Nos termos da lei, as autoridades municipais avaliarão o progresso da criança. Os testes, aplicados normalmente por um professor em uma escola local, consistirão em uma ou mais provas de desempenho. Os pais que oferecem educação insatisfatória ou sinais dela receberão uma multa (Blok \& Karsten, 2011, p. 145).

$\mathrm{Na}$ França, os pais estão legalmente autorizados a fornecer a educação domiciliar, mas devem registar-se anualmente no seu município e no órgão de inspeção acadêmica (Inspection Académique). Podem escolher os seus métodos de ensino-aprendizagem, mas a lei exige que 


\section{pro.posições}

$e$-ISSN 1980-6248

ofereçam uma ampla gama de assuntos, incluindo francês, matemática, pelo menos uma língua estrangeira, artes e educação esportiva, e é esperado que, aos 16 anos, o adolescente atinja um nível de desempenho e aprendizagem comparável à educação escolar. Anualmente os estudantes devem ser avaliados por meio de uma entrevista pessoal com um inspetor, o que geralmente ocorre em domicílio. Os inspetores devem respeitar a liberdade pedagógica, incluindo variada progressão. Não há nenhuma obrigação legal de aplicar testes às crianças em diferentes disciplinas. No entanto, alguns inspetores propõem testes escritos que variam de acordo com a região, o que provoca grande debate. Se uma avaliação negativa é emitida, uma segunda inspeção segue, e, se o resultado ainda for negativo, os pais devem matricular a criança na escola.

A Alemanha é o país europeu mais restritivo quanto à educação domiciliar: a educação é regulamentada em nível federal, e cada estado prevê a escolaridade obrigatória, quer na Constituição, quer nas leis mais importantes, cuja matéria trata de educação (Spiegler, 2003, 2009, como citado em Blok \& Karsten, 2011, p.146). Exceções só são possíveis para crianças cujas profissões dos pais forcem a família a se movimentar ou que estejam doentes por longos períodos, bem como para crianças imigrantes que apenas permaneçam na Alemanha por um curto período. O ensino para os primeiros dois grupos é oferecido por um professor de uma escola estadual que visita a casa da família duas ou três vezes por semana. As sanções por fugir da escolaridade obrigatória variam por estado e podem incluir multas, penas de prisão e até mesmo perda do poder familiar.

$\mathrm{Na}$ Irlanda, está prescrito na Constituição que cada criança tem o direito a um mínimo de educação moral, intelectual e social, e os pais são livres para escolher entre a escolarização e a educação domiciliar. Se eles optarem por esta, deverão se registrar no Conselho Nacional de Educação e Bem-Estar e, no ato do registro, indicar como irão fornecê-la. O registro negado poderá ser objeto de recurso. A fiscalização é da responsabilidade do conselho supracitado e prevê duas fases de avaliação. Na primeira (avaliação preliminar), o processo de ensinoaprendizagem é avaliado em cooperação com os pais, e não é necessário visitar o local onde a educação é fornecida ou encontrar a criança, embora as visitas domiciliares ocorram na maior parte dos casos. A segunda fase (avaliação global) só é solicitada se o primeiro estágio não tiver sido satisfatório, e pressupõe visitar a casa e se envolver com a criança. Se, mesmo depois da avaliação abrangente, se considera que a educação não cumpre os requisitos 


\section{pro.posições}

$e$-ISSN 1980-6248

estabelecidos, a decisão poderá ser objeto de recurso. Essa comissão de apelação poderá prescrever aos pais que cumpram com quaisquer requisitos que julgar adequados.

Na Itália, a educação domiciliar segue o artigo 30 da Constituição, segundo o qual é direito e dever dos pais manter, instruir e educar as crianças, mesmo aquelas nascidas fora do casamento. A escolaridade obrigatória poderá ser cumprida mediante comparecimento às escolas públicas, às escolas particulares ou poderá ser cumprida pela educação domiciliar, mediante a autorização do diretor da escola competente. Mas os pais que optam por esse modelo devem oferecer relatório para o prefeito e o diretor da escola da sua região, comprovando anualmente sua competência técnica ou econômica para promover a educação domiciliar.

Segundo a justificativa, a inspeção pública garantiria o interesse social geral de que todos aqueles em idade escolar possam adquirir conhecimentos e habilidades por meio do ensino oferecido por indivíduos qualificados e, para isso, seria necessário ainda verificar periodicamente o que o aluno aprendeu. No protocolo de inspeção, destaca-se que a única maneira de avaliar a capacidade dos pais de oferecer educação em casa é através da avaliação do aprendizado da criança por meio de exames para acessar a série seguinte, independentemente de os estudos serem continuados em particular ou em uma escola pública. Dessa forma, um registro sistemático e longitudinal do progresso do aluno é compilado.

A Holanda é outro dos poucos países europeus onde a educação domiciliar não é uma forma aceitável de cursar o ensino obrigatório, e a educação escolar é o único modelo permitido. A lei de educação obrigatória, no entanto, contém uma disposição segundo a qual os pais podem ser dispensados de efetuar a matrícula da criança, se não houver escola de sua religião ou convicção dentro de uma distância razoável de sua residência. Como essa lei não contém qualquer outra disposição quanto à educação dessas crianças, pais que obtiverem o benefício são livres para educá-los domiciliarmente (Sperling, 2010, como citado em Blok \& Karsten, 2011, p.147).

Não existe legislação que preveja a inspeção domiciliar por parte das autoridades públicas de inspeção escolar. Ocasionalmente, o "Protection Services Dutch" investiga famílias para determinar se as crianças devem ser matriculadas na escola, apesar do benefício 


\section{pro.posições}

$e$-ISSN 1980-6248

da isenção. A jurisdição desses serviços é orientada por um dispositivo constante do Código Civil holandês, que afirma que os pais são responsáveis pela educação dos seus filhos.

O serviço apenas adota medidas restritivas se for relatado que uma criança está em perigo, o que nem sempre foi assim, porque crianças não escolarizadas eram casos que costumeiramente levavam à proposição de ações judiciais. Com o passar do tempo, entretanto, os juízes e tribunais passaram a entender que formas alternativas à educação escolar e o simples fato de a criança não estar matriculada na escola, em si mesmos não se constituem como situações de risco à criança. Não obstante, em 2003 o governo lançou um debate público sobre a educação domiciliar, considerando a introdução de procedimentos específicos de inspeção da educação domiciliar.

$\mathrm{Na}$ Noruega, a educação domiciliar é legalmente reconhecida. Deverá ser equivalente à educação escolar, e os pais deverão informar ao município a sua opção. A inspeção do processo de ensino-aprendizagem também é prescrita em lei, e os municípios têm responsabilidade e liberdade significativa no que diz respeito à sua organização. Uma abordagem típica envolve uma visita domiciliar por professores supervisores duas vezes ao ano, ocasião em que, baseados em conversas com os pais, formam uma opinião sobre a qualidade do ensino fornecido. Se permanecerem em dúvida, eles poderão submeter a criança a um teste, e, caso verifiquem que a qualidade da educação domiciliar não é satisfatória, ela deverá frequentar a escola.

Em Portugal, a educação domiciliar é legal, e os pais, quando desejam ensinar seus filhos domiciliarmente, devem procurar a escola da área e mostrar que são competentes para a função. Nesse caso, a escola deverá dar-lhes o acesso a programas e outros documentos relevantes para o ensino e, ao final de cada ano letivo, os pais devem apresentar as avaliações realizadas e seus resultados. No final de cada ciclo de escola $\left(4 .^{\circ}, 6 .^{\circ}\right.$ e $9 .^{\circ}$ anos), a criança deverá ser submetida a exames como qualquer outro aluno vinculado à escola.

Na Suécia, a lei permite a educação domiciliar "em extraordinárias circunstâncias", devendo os pais do educando solicitar ao órgão de ensino permissão renovável anualmente. Se permitida, deverão oferecer uma alternativa adequada à educação escolar e, ao final do ano letivo, as crianças deverão ser avaliadas antes de prosseguir estudando domiciliarmente no ano seguinte. O currículo a ser seguido deverá ser discutido com funcionários do Estado, e 


\section{pro.posıções}

$e$-ISSN 1980-6248

autoridades municipais fiscalizarão e supervisionarão as famílias em duas inspeções anuais, conforme previsão legal. Se os pais não cumprirem os requisitos, a sua autorização poderá ser recusada.

\section{No Brasil}

Não há no ordenamento jurídico brasileiro em vigor nenhuma norma jurídica que tenha como conteúdo ou objeto a Educação Domiciliar, seja em caráter permissivo ou proibitivo, e o entendimento dominante e quase pacífico dos sistemas de ensino e do sistema de proteção, promoção e garantia de direitos da criança e do adolescente no Brasil é de que "lugar de criança é na escola" e que a escolarização está constituída, em nosso ordenamento jurídico $^{7}$, como um direito público subjetivo da criança e do adolescente, seu direito fundamental à educação. E é dever do Estado, de seus órgãos e agentes e dos pais ou responsáveis matricular as crianças a partir de 4 anos na escola e zelar por sua frequência no percentual legal de dias letivos ${ }^{8}$.

Essa busca por escolarizar cada vez mais, em nosso entendimento, confunde educação com escolarização e ensino; e se esquece de realizar as necessárias digressões históricas e lógicas para perceber as nuanças que impedem de alcançar as finalidades da educação nacional pelo simples acréscimo de anos à escolarização obrigatória e pela certificação estatal (Andrade, 2014). Porém, na contramão desse movimento, encontram-se os processos normativos em curso no Congresso Nacional e no Supremo Tribunal Federal, que visam a retirar da ilegalidade o crescente movimento internacional e nacional de pais que operam em favor da promoção da educação e do ensino, sob o seu protagonismo, de modo desescolarizado.

$\mathrm{Na}$ esfera da jurisdição, é conhecida uma única sentença judicial que adentrou ao mérito da ação favorável à prática de educação domiciliar no Brasil. Publicada no Diário da

\footnotetext{
${ }^{7}$ As normas jurídicas que mais frequentemente são citadas para fundamentar a escolarização obrigatória no Brasil são os artigos 205 a 210 da Constituição Federal, artigos 1. a 7. ${ }^{\circ}$ da Lei de Diretrizes e Bases da Educação Nacional (Lei 9.394/96) e os artigos 1. ${ }^{\circ}$ ao 6. ${ }^{\circ}$ e 93 a 97, do Estatuto da Criança e do Adolescente (Lei 8.069/90).

8 A Emenda Constitucional n. ${ }^{\circ}$ 59/2009 reduziu para quatro anos a idade de escolarização obrigatória e tornou obrigatória a oferta gratuita de educação básica a partir dos 4 anos de idade. A Lei n. ${ }^{0}$ 12.796/2013, que a seguiu, também estabelece que a Educação Infantil, que contempla crianças de 4 e 5 anos na pré-escola, será organizada com carga horária mínima anual de 800 horas, distribuída por, no mínimo, 200 dias letivos. $\mathrm{O}$ atendimento à criança deve ser de, pelo menos, quatro horas diárias para o turno parcial e sete para a jornada integral, seguindo o que já estava estabelecido para o Ensino Fundamental e Médio.
} 


\section{pro.posições}

$e$-ISSN 1980-6248

Justiça de São Paulo em 4 de agosto de 2016, a decisão, sob recurso ao Tribunal de Justiça de São Paulo, decidiu sobre o pedido do Ministério Público local, que consistia em que as três filhas do casal processado fossem matriculadas em escola e obrigadas por eles a frequentá-la, sob pena de multa diária. Na decisão, o magistrado permitiu que as duas crianças (4 e 11 anos), e a adolescente (16), continuem o processo de ensino-aprendizagem pelo modelo domiciliar, sem a obrigação de realizar matrícula escolar?.

No escopo nacional, no Supremo Tribunal Federal encontra-se em curso o Recurso Extraordinário n. ${ }^{\circ} 888.815 / \mathrm{RS}$, interposto por uma família do Rio Grande do Sul, pelo qual os pais pedem que seja reconhecido o seu direito de educar sua filha domiciliarmente, sem matrícula ou frequência escolar, por diversas razões, inclusive aquelas ligadas à liberdade religiosa. $\mathrm{Na}$ origem, foi impetrado, sem sucesso, Mandado de Segurança contra o dirigente de ensino local, que exigia a matrícula e a frequência da estudante na escola. O relator do Recurso no STF, Ministro Luis Roberto Barroso, deu o caráter de repercussão geral ao processo, pois julgou matéria do interesse constitucional "saber se o ensino domiciliar (bomeschooling) pode ser proibido pelo Estado ou viabilizado como meio lícito de cumprimento, pela família, do dever de prover educação, tal como previsto no artigo 205 da CRFB/1988” (STF, 2015).

A decisão do tribunal poderá definitivamente julgar pela constitucionalidade ou inconstitucionalidade do direito dos pais à opção pelo modelo de educação domiciliar, o que reforçará determinantemente o entendimento atual. Caso se decida pela constitucionalidade, muito provavelmente se remeterá ao legislador infraconstitucional o dever-poder de regulamentar o direito à educação domiciliar.

Nessa mesma linha, encontram-se os projetos de lei mais recentes no Congresso Nacional. Barbosa (2013, p.10) nos lembra do Projeto de Lei 3.518/2008, de autoria dos

\footnotetext{
9 "Infância e Juventude RELAÇÃO No 0659/2016 JUÍZO DE DIREITO DA 1ª VARA CRIMINAL JUIZ(A) DE DIREITO EDUARDO RUIVO NICOLAU ESCRIVÃ(O) JUDICIAL ANDRE LUIZ FERNANDES MARQUES EDITAL DE INTIMAÇÃO DE ADVOGADOS -

Processo 0003659-22.2015.8.26.0477 - Medidas de Proteção à Criança e Adolescente - Matrícula e frequência obrigatória em estabelecimento oficial de ensino fundamental - A.M. e outro - Diante do exposto, por entender que as menores $\mathrm{G}, \mathrm{M}$ e B encontram-se devidamente inseridas em processo de aprendizagem, por meio da metodologia homeschooling; que tal modalidade de ensino não afronta normas constitucionais e infraconstitucionais; que compete primordialmente aos pais a obrigação de educar os filhos e que é descabida a intervenção estatal no caso em comento, JULGO IMPROCEDENTES os pedidos formulados na representação. - ADV: EDISON PRADO DE ANDRADE (OAB 200389/SP). "
} 


\section{pro.posições}

$e$-ISSN 1980-6248

Deputados Henrique Afonso e Miguel Martini, rejeitado na Câmara dos Deputados. O projeto assim modificava a $\mathrm{LDB}$ em vigor, em seu artigo 81:

Art. $81[\ldots]$

Parágrafo Único - É admitida e reconhecida a modalidade de educação domiciliar, no nível básico, desde que ministrada no lar por membros da própria família ou guardiães legais e obedecidas as disposições desta Lei. É dever do Estado facilitar, não obstruir, essa modalidade educacional. [ênfase no original].

I- Os pais ou responsáveis por crianças ou adolescentes em regime de educação domiciliar deverão usar os serviços de uma escola institucional como base anual para avaliação do progresso educacional, conforme regulamentação dos sistemas de ensino.

II- A avaliação dar-se-á em conformidade com as diretrizes nacionais estabelecidas nesta Lei e currículos nacionais normatizados pelo Conselho Nacional de Educação.

III- Os pais serão responsáveis perante a escola pelo rendimento das avaliações do estudante em regime de educação domiciliar. Se as notas dos testes básicos de leitura, escrita e matemática da criança ou o adolescente forem abaixo do mínimo do rendimento escolar nacional, no final do ano a licença para a educação em casa será mudada para licença temporária, dando-se aos pais ou guardiães mais um ano escolar de recuperação a fim de que o estudante possa tirar notas conforme ou acima do mínimo de rendimento escolar nacional. Caso contrário, a licença para educar em casa será cancelada no final do ano escolar de recuperação e a criança deverá freqüentar uma escola institucional no ano escolar seguinte.

A proposta de Emenda Constitucional n. ${ }^{\circ} 444 / 2009$, que acrescenta o $\int 4 .^{\circ}$ ao art. 208 da Constituição Federal, dispõe que o Poder Público deverá regulamentar a educação domiciliar, "assegurado o direito à aprendizagem das crianças e jovens na faixa etária da escolaridade obrigatória por meio de avaliações periódicas sob responsabilidade da autoridade educacional"10. Além dessa proposta, que entende necessária a modificação do texto constitucional para fazer valer o direito à educação domiciliar, encontra-se na Câmara dos Deputados o projeto de lei de n. ${ }^{o}$ 3.179/2012, de autoria do deputado Lincoln Portela, que altera a Lei 9.394/96. O Projeto de Lei disciplina a Educação Domiciliar no País e previa, em

\footnotetext{
${ }^{10}$ Retirado em agosto de 2012, de <http://www.camara.gov.br/proposicoesWeb/prop_mostrarintegra?codteor $=723417$ \&filename $=\mathrm{PEC}+444 / 2009>$.
} 


\section{pro.posıções \\ $e$-ISSN 1980-6248}

uma elaboração inicial (informação pessoal) ${ }^{11}$, regulamentação ao artigo 205 da Constituição

Federal. Assim estava previsto:

Artigo 1.': Os pais ou responsáveis do menor têm a primazia na escolha do gênero de educação a ser ministrado aos filhos ou quaisquer outros menores sob sua guarda;

Artigo 2. ${ }^{\circ}$ É facultado aos pais ou responsáveis determinar se a educação será realizada domiciliarmente ou no sistema escolar, público ou privado;

\1. ${ }^{\circ}$ É possível optar por modelo de educação misto, parcialmente domiciliar e escolar;

\2..$^{\circ}$ É livre a transferência do menor, a qualquer tempo, da educação escolar para a educação domiciliar e vice-versa;

Artigo $3^{\circ}$ : A opção referida no artigo anterior deve ser expressa, formalizando-se por meio de matrícula na instituição pertinente, no caso de educação escolar, ou comunicado formal à secretaria de educação do município, no caso de educação domiciliar.

Parágrafo único. A matrícula e o comunicado referentes aos menores entre quatro e dezessete anos devem ser renovadas anualmente.

Artigo $4 .^{\circ}$ : É dever dos pais ou responsáveis que optarem pela educação domiciliar registrar, em arquivo próprio, o conteúdo ministrado domiciliarmente.

Parágrafo único. O conselho tutelar poderá, a qualquer tempo, verificar o cumprimento desse requisito.

Artigo 5. ${ }^{\circ} \mathrm{O}$ direito à educação domiciliar poderá ser temporariamente suspenso ou cassado se for verificado, por meio de processo administrativo ou judicial:

I - o descumprimento reiterado do requisito previsto no artigo anterior;

II - a ocorrência de maus-tratos;

III - a manifesta ausência de instrução compatível com a faixa etária dos filhos ou de quaisquer outros menores sob guarda.

Parágrafo único. Qualquer atentado à liberdade educacional dos pais fora das hipóteses previstas no caput deste artigo configura abuso de autoridade, punido nos termos da Lei n. ${ }^{\circ}$ 1.898, de 1968.

\footnotetext{
${ }^{11}$ No princípio do ano de 2013, em audiência pública sobre a Educação Domiciliar na Câmara dos Deputados, um assessor parlamentar da Casa nos informou que este Projeto de Lei sofrera diversas mudanças, dentre elas a retirada do Conselho Tutelar como órgão fiscalizador da prática da Educação Domiciliar.
} 


\section{pro.posıções \\ $e$-ISSN 1980-6248}

Artigo 6. ${ }^{\circ}$ Esta lei entra em vigor na data de sua publicação. (Projeto de lei BR, 2012)

O Projeto inicial foi modificado. A mudança mais significativa consiste na transferência do poder discricionário quanto à escolha pela educação domiciliar, que antes pertencia aos pais da criança e, nos termos do novo projeto, passaria a ser dos sistemas de ensino federal, estaduais, municipais ou distritais, os quais poderiam autorizar e regulamentar a educação domiciliar no âmbito de suas competências constitucionais e legais. Toda a regulamentação pensada anteriormente em termos de garantia dos direitos dos pais doravante seria prerrogativa dos sistemas de ensino, que adquiriu amplos poderes discricionários em relação aos pais. Assim dispõe o Projeto de Lei (BR, 2012):

O Congresso Nacional decreta:

Art. 1. ${ }^{\circ}-$ O art. 23 da Lei n. ${ }^{\circ}$ 9.394, de 20 de dezembro de 1996, passa a vigorar acrescido do seguinte parágrafo:

Art. 23...

$\int 3^{\circ}$ É facultado aos sistemas de ensino admitir a educação básica domiciliar, sob a responsabilidade dos pais ou tutores responsáveis pelos estudantes, observadas a articulação, supervisão e avaliação periódica da aprendizagem pelos órgãos próprios desses sistemas, nos termos das diretrizes gerais estabelecidas pela União e das respectivas normas locais.

Art. 2. ${ }^{\circ}$ Esta lei entra em vigor na data de sua publicação.

Mais recentemente, outro parlamentar, o deputado Eduardo Bolsonaro, propôs o PL 3.261/2015. O PL prevê a matrícula dos estudantes domiciliares na rede pública ou privada de ensino, mas não deixa qualquer dúvida sobre o tratamento diferenciado que deverá ter o aluno matriculado em regime de escolarização em relação ao aluno em regime domiciliar. Este deverá cumprir apenas o calendário de avaliações, ficando desobrigado da frequência diária e do cumprimento da carga horária tradicional. O texto ainda diz que caberá a cada instituição de ensino expedir históricos escolares, declarações de conclusão de série e diplomas ou certificados de conclusão de cursos aos alunos previamente matriculados em regime de ensino disciplinar.

O Projeto de Lei Substitutivo aos projetos de lei n. ${ }^{\circ} 3.179$, de 2012, e n. ${ }^{\circ} 3.261$, de 2015, altera a Lei de Diretrizes e Bases da Educação Nacional para dispor sobre a possibilidade de oferta domiciliar da educação básica, e é de autoria da deputada Dorinha 


\section{pro.posições}

$e$-ISSN 1980-6248

Seabra Rezende. Sua redação vem sendo modificada ao longo do tempo em meio às discussões na Câmara Federal. As mais importantes prescrições no texto atual envolvem a obrigatoriedade de matrícula dos estudantes em escola pública, registro da família e inspeção domiciliar, a ser realizada pelo órgão competente do sistema de ensino. Assim, são os seguintes os direitos e os deveres prescritos no projeto de lei substitutivo:

- É admitida a educação básica domiciliar, sob a responsabilidade dos pais ou tutores responsáveis pelos estudantes, observadas a articulação, a supervisão e a avaliação periódica da aprendizagem pelos órgãos próprios dos sistemas de ensino.

- Obrigatoriedade de matrícula do estudante em escola pública.

- Manutenção de registro oficial das famílias optantes pela educação domiciliar.

- Participação do estudante nos exames realizados nacionalmente e nos exames do sistema estadual ou sistema municipal de avaliação da educação básica, quando houver.

- Previsão de inspeção educacional, pelo órgão competente do sistema de ensino, no ambiente em que o estudante estiver recebendo a educação domiciliar.

- Controle de frequência a cargo da escola ou pela instituição de educação pré-escolar, conforme o disposto no seu regimento e nas normas do respectivo sistema de ensino.

- O ensino fundamental será presencial, sendo o ensino a distância utilizado como complementação da aprendizagem ou em situações emergenciais e, ainda assim, mediante autorização dada pelos sistemas de ensino.

\section{Considerações do autor}

A liberdade de escolha da prática de educação domiciliar, bem como a determinação de limites, modos e agentes de controle estatais, encontra muita discussão na literatura e na legislação internacional. A questão está posta normalmente em torno da tríade "Família ou Estado ou Criança/Adolescente" e gira em torno dos direitos de liberdade individual, em sua contraposição aos direitos sociais e ao interesse público. Nesse passo, alguns entendem que deverá prevalecer o interesse do Estado; outros, a opção dos pais; e outros, o interesse estrito da criança. 


\section{pro.posições}

$e$-ISSN 1980-6248

Qualquer que seja o ponto de vista, é possível verificar posições favoráveis ou contrárias à adoção do modelo, e todos os argumentos mostram-se plausíveis: direito fundamental dos pais; poder familiar; poder do Estado; privacidade e intimidade familiar; alfabetização e tolerância como um interesse de Estado; regulamentação do direito privado dos pais sob determinados critérios; e interesse primordial da criança.

Do nosso ponto de vista, não há como não olhar a questão sob a perspectiva da pessoa em desenvolvimento - a criança ou adolescente -, o seu direito fundamental à educação e os seus demais direitos fundamentais, especialmente o direito à convivência familiar e comunitária, que - tal como entendemos que lhe garantem muitos dispositivos da Constituição e da legislação nacional, e vem sendo reconhecido insistentemente pela literatura que se debruça sobre a análise da sociedade atual pós-moderna e pós-industrial, sociedade de massa e prevalência da cultura e de indivíduos narcisistas, bem como de outros tipos (De Masi, 1999, pp. 11-97) - tem sido sistematicamente negado, pelas famílias e pela sociedade brasileira, a crianças e adolescentes.

Ademais, muito embora seja a educação das crianças e dos adolescentes um dever do Estado e da família (Constituição [CF] BR, 1988, art. 205), entendemos que o dever prioritário de prover e garantir a educação de cada criança e adolescente repousa sobre os ombros dos seus respectivos pais e mães, e não sobre os poderes e as instituições de Estado, dever esse que consiste em "assistir, criar e educar os seus filhos menores", conforme prescreve a Lei Maior (CF BR, 1988, art. 229). Não têm o artigo 227 da Constituição Federal - que prescreve o dever compartilhado de assegurar com absoluta prioridade os direitos da criança e do adolescente -, o artigo 205 supracitado, ou qualquer outro dispositivo infraconstitucional, o condão de afastar dos pais a suprema responsabilidade quanto ao pleno desenvolvimento de seus filhos, responsabilidade essa que se reforça, em nossa opinião, diante das condições sociais atuais.

Aos pais que reconhecem esses deveres e zelam por garantir aos seus filhos esses direitos não poderá ser negado fazer a escolha entre ensinar e educar seus filhos na esfera do recôndito domiciliar e comunitário - segundo seus próprios esforços e protagonismo, valendo-se do apoio técnico dos profissionais de educação, das escolas e dos sistemas de ensino e das melhores e mais recentes técnicas e recursos pedagógicos - ou sob o 


\section{pro.posıções}

$e$-ISSN 1980-6248

protagonismo das instituições de ensino e das unidades escolares, em plena sujeição às normas que emanam das instâncias superiores de ensino no País e do sistema político.

Quanto ao papel do Estado, entendemos que sua função social ${ }^{12}$ é subsidiária às obrigações que se inserem na esfera do poder familiar, devendo limitar-se a garantir que seja provido por meio da educação ou por qualquer outro meio o pleno desenvolvimento físico, mental, moral, social e espiritual das crianças e dos adolescentes que se encontram no território brasileiro, tal como prescreve o artigo 3. ${ }^{\circ}$ da Lei 8.069/90 13 (Lei BR, 1990), operando apenas nos casos nos quais se evidencia conduta culposa dos seus genitores ou responsáveis legais, ou mesmo quando esses não dispõem de condições próprias para prover-lhes o melhor desenvolvimento possível.

Tendo isso em mente, passaremos a descrever as diretrizes que entendemos que deverão nortear o reconhecimento do Estado brasileiro quanto ao direito à educação domiciliar, aqui se incluindo os três poderes republicanos em sua multiplicidade de órgãos, agentes e funções.

Em primeiro lugar, entendemos que deverá ser concedida a autorização dos órgãos dos sistemas de ensino aos pais mediante simples comunicação à diretoria de ensino pela escolha da educação domiciliar, sendo desnecessária avaliação prévia deles.

A esse respeito, entendemos que o Estado não poderá presumir que o pai, a mãe, ou o responsável legal que queiram praticar o modelo educacional domiciliar não saibam fazê-lo porque não ostentam títulos acadêmicos de nível superior, independentemente do estágio de aprendizagem no qual se encontra a criança ou adolescente. Possivelmente essa será a tendência dos órgãos de ensino no Brasil, caso o projeto substitutivo atual ou mesmo o projeto original se mantenha como está. Entretanto, não vislumbramos nenhuma coerência possível no fato de o Estado brasileiro permitir que pais ensinem seus filhos de modo domiciliar e, ao mesmo tempo, exigir que eles sejam detentores de certificados que atestam sua escolarização, como condição para que os pais promovam a educação domiciliar com seus filhos.

12 Adotamos como paradigma teórico a teoria funcionalista, tal como disposto em Bobbio (1997, pp.58-60).

13 “Art. 3. - A criança e o adolescente gozam de todos os direitos fundamentais inerentes à pessoa humana, sem prejuízo da proteção integral de que trata esta Lei, assegurando-se-lhes, por lei ou por outros meios, todas as oportunidades e facilidades, a fim de lhes facultar o desenvolvimento físico, mental, moral, espiritual e social, em condições de liberdade e de dignidade". 


\section{pro.posições}

$e$-ISSN 1980-6248

Ainda nesse mesmo sentido, entendemos ser completamente razoável presumir que os pais que optam pela educação domiciliar e não se furtam a se apresentar formalmente perante a autoridade de ensino estatal (uma vez regularizada a situação atual de vazio legal quanto ao direito à educação domiciliar) estejam suficientemente motivados e empenhados em prover os melhores meios, instrumentos e conhecimentos para promover a educação de seus filhos.

Assim sendo, no ato da comunicação o órgão público registrará qual o adulto que será o responsável pelo ensino da criança, se o pai ou a mãe. Esse registro é necessário, com vistas a preservar a criança e o seu direito à educação no caso de eventual separação ou divórcio dos pais, e ele deverá ser levado em consideração, ao serem fixados os direitos de guarda e visitas da criança ou do adolescente nessa hipótese.

Em segundo lugar, matrícula da criança em escola específica, pública ou privada, escolhida pelos pais ou responsáveis legais da criança, exigência necessária apenas caso os pais do estudante, e ele mesmo, tenham interesse em participar de alguma atividade escolar, hipótese na qual a frequência da criança ou adolescente à escola deverá ser ajustada em comum acordo com os gestores escolares, e conforme a demanda do próprio processo de ensino-aprendizagem. Essa medida é necessária para que os pais saibam onde poderão encontrar apoio pedagógico e possibilidade de participação da criança em outras atividades escolares, que não necessariamente a sala de aula.

Assim, o projeto pedagógico da escola que deverá contemplar a educação domiciliar deverá prever ações de apoio, acompanhamento e avaliação das crianças/adolescentes que estudam em regime domiciliar, tudo de modo consentâneo com os princípios de liberdade e os ideais de solidariedade humana, inspiradores dos processos educacionais desenvolvidos no Brasil republicano (Art. 2. ${ }^{\circ}$ da Lei de Diretrizes e Bases da Educação Nacional).

Em terceiro lugar, e com vistas a assegurar o sucesso do processo de ensinoaprendizagem desenvolvido domiciliarmente, realização de avaliação de resultado, aplicada exclusivamente ao estudante, a qual deverá levar em conta que o modelo domiciliar não segue rigidamente o modelo idade-série e o currículo fundado no desenvolvimento de competências 


\section{pro.posições}

$e$-ISSN 1980-6248

meramente cognitivas, pois já existem, no campo da teoria pedagógica e da psicologia do desenvolvimento, críticas suficientes à adoção desses modelos pelos sistemas de ensino ${ }^{14}$.

A primeira avaliação de resultado poderá ser aplicada seis meses após a comunicação e a matrícula do estudante, seguindo-se avaliações anuais. Poderá ser complementada com uma visita domiciliar de professor qualificado, se constatada, por meio da avaliação do estudante, a inépcia dos pais. Na visita, o professor poderá aplicar nova avaliação e, caso ainda assim ela demonstre resultados significativos abaixo da média, a criança/adolescente deverá voltar a frequentar presencialmente a escola. Nesse caso, os pais apenas poderão voltar a praticar educação domiciliar caso sejam aprovados em um exame de proficiência nos domínios e nas linguagens nos quais a criança apresentou maiores dificuldades de aprendizado.

Finalizando, e considerando a previsão de significativa redução de custos orçamentários públicos com a manutenção do sistema escolar ante a diminuição do número de alunos que frequentam regularmente a escola, acreditamos ser possível que os sistemas de ensino aproveitem a estrutura já existente para aperfeiçoamento e capacitação de professores, com vistas a programarem um núcleo de estudo e capacitação para a educação domiciliar. Para isso, poder-se-á contar com o apoio das Instituições de Ensino Superior que têm acolhido pesquisas do tipo no Brasil e no exterior.

Ao mesmo tempo, inclusive em atenção ao novo paradigma de relacionamento público-privado, entendemos desejável que os sistemas de ensino e entidades associativas de pais e educadores formalizem parceria destinada a promover a educação domiciliar no Brasil, não apenas como forma de conhecer esse fenômeno social e pedagógico ainda pouco conhecido no País, mas também como meio de oferecer apoio pedagógico aos pais que dele necessitarem, sempre tendo em vista o princípio da prioridade absoluta dos direitos da criança e do adolescente (art. 227 da CRFB), e do interesse superior da criança e do adolescente, os quais deverão sempre suplantar quaisquer outros interesses econômicos ou políticos - ainda que legítimos - e prevalecer sobre eles.

\footnotetext{
14 De forma coerente com os modos e os princípios pedagógicos que têm embalado muitos pais que praticam educação domiciliar no Brasil (Andrade, 2014, pp. 93-101), entendemos que o paradigma a ser considerado para o desenvolvimento e a avaliação do processo de ensino-aprendizagem não poderá ser o que prima pela fixação e apreensão de conteúdos e informações, mas sim os novos paradigmas trazidos na esteira da psicologia desenvolvimentista, como os paradigmas das Inteligências Múltiplas (Gardner, 1994) e da Inteligência Emocional (Goleman, 1995).
} 


\section{pro.posições}

$e$-ISSN 1980-6248

\section{Referências}

Andrade, Édison E. P. de. Educação familiar desescolarizada e o direito da criança e do adolescente: relevância, limites e possibilidades na ampliação do direito à educação. Tese de Doutorado. Faculdade de Educação da Universidade de São Paulo, São Paulo. Retirado em 13 de maio de 2016, de http://www.teses.usp.br/teses/disponiveis/48/48134/tde-10112014-111617/ptbr.php.

Barbosa, L. M. R. Ensino em casa no Brasil: análise histórica de seus aspectos legais. Recuperado em 13 de maio de 2016, de http://www.anpae.org.br/congressos_antigos/simposio2009/184.pdf.

Blok, H., \& Karsten, S. (2011). Inspection of home education in European countries. European Journal of Education, 46(1), Part II, 138-52.

Bobbio, N. (1997). Estado, governo e sociedade: para uma teoria geral da política (6a ed.). Rio de Janeiro: Paz e Terra.

Corwin, E. S. (1986). A Constituição norte-americana e seu significado atual (Lêda Boechat Rodrigues, pref., trad. e notas). Rio de Janeiro: Jorge Zahar.

De Masi, D. (Org.) (1999). A sociedade pós-industrial. São Paulo: Editora Senac.

Gardner, H. (1994). Estruturas da mente: a teoria das múltiplas inteligências. Porto Alegre: Artes Médicas. Publicado originalmente em inglês com o Título original: The frames of the mind: the theory of multiple intelligences. 1983.

Goleman, D. (1995). Inteligência emocional - a teoria revolucionária que redefine o que é ser inteligente. Rio de Janeiro: Objetiva.

Kunzman, R., \& Gaither, M. (2013). Homeschooling: A comprehensive survey of the research. Other Education: The Journal of Educational Alternatives, 2(1), 4-59. ISSN 2049-2162. 


\section{pro.posições}

$e$-ISSN 1980-6248

\section{Legislação}

Constituição da República Federativa do Brasil de 1988 (1988). Brasília: Presidência da República. Casa Civil. Subchefia para Assuntos Jurídicos.

Lei BR n. ${ }^{\circ}$ 8.069, de 13 de julho de 1990. Dispõe sobre o Estatuto da Criança e do Adolescente e dá outras providências. Presidência da República. Casa Civil. Subchefia para Assuntos Jurídicos.

Projeto de Lei BR 3.179/2012. Acrescenta parágrafo ao art. 23 da Lei n. ${ }^{\circ}$ 9.394, de 1996, de diretrizes e bases da educação nacional, para dispor sobre a possibilidade de oferta domiciliar da educação básica. Brasília: Câmara dos Deputados, 8 de fevereiro de 2012.

Projeto de Lei BR 3.261/2015. Autoriza o ensino domiciliar na educação básica, formada pela educação infantil, ensino fundamental e ensino médio para os menores de 18 (dezoito) anos, altera dispositivos da Lei n. ${ }^{\circ}$ 9.394, de 20 de dezembro de 1996, que estabelece as diretrizes e bases da educação nacional, e da Lei n. ${ }^{\circ}$ 8.069, de 13 de julho de 1990, que dispõe sobre o Estatuto da Criança e do Adolescente e dá outras providências. Brasília: Câmara dos Deputados, 8 de outubro de 2015.

Projeto de Lei BR Substitutivo aos projetos de lei n. ${ }^{\circ}$ 3.179, de 2012, e n. ${ }^{\circ} 3.261$, de 2015. Altera a Lei n. ${ }^{\circ}$ 9.394, de 1996, de diretrizes e bases da educação nacional, para dispor sobre a possibilidade de oferta domiciliar da educação básica. Brasília: Câmara dos Deputados, 24 de novembro de 2015.

Proposta BR n. ${ }^{\circ}$ 444/2009 de Emenda à Constituição. Acrescenta o $\int 4 .^{\circ}$ ao art. 208 da Constituição Federal. Dispõe sobre a regulamentação da educação domiciliar. Brasília: Câmara dos Deputados, 08 de dezembro de 2009.

Submetido à avaliação em 20 de junho de 2016; aceito para publicação em 05 de maio de 2017. 